\title{
Segmenting Small-Business Customers: The Role of Socially Related Traits-An Abstract
}

\author{
Shaked Gilboa and Tali Seger Guttman
}

\begin{abstract}
Previous research has examined the different reasons why customers remain loyal to small businesses. These have mainly been explained by constructs related to the nature of small businesses such as personal attention, familiarity, and informality as well as the uniqueness of their products. However, little research has been done on the potential effects of customers' own characteristics on their loyalty to small businesses. Specifically, no study has linked customers' personality traits and aspects of sociability to their preference for small businesses. Following this, the current study employs mixed-method approach to test how customers' socially related traits impact their trust and loyalty to small business. In the first stage, a preliminary qualitative phase based on interviews with both small businesses' owners and customers aimed to identify general characteristics and behaviors of loyal customers. In the second stage, a quantitative study categorized small business customers based on their degree of extroversion and need for affiliation vs. loneliness.
\end{abstract}

S. Gilboa $(\bowtie) \bullet$ T.S. Guttman

Ruppin Academic Center, Israel

e-mail: shakeg@ ruppin.ac.il; talis@ ruppin.ac.il 